\title{
Team-based instructional change in undergraduate STEM: characterizing effective faculty collaboration
}

\author{
Diana Sachmpazidi 1,2* (D), Alice Olmstead ${ }^{1,3}$, Amreen Nasim Thompson ${ }^{3}$, Charles Henderson ${ }^{1,2,4}$ and \\ Andrea Beach ${ }^{1,5}$
}

\begin{abstract}
Background: Team-based instructional change is a promising model for improving undergraduate STEM instruction. Teams are more likely to produce sustainable, innovative, and high-quality outcomes than individuals working alone. However, teams also tend to involve higher risks of failure and can result in inefficient allocation of valuable resources. At this point, there is limited knowledge of how teams in the context of STEM higher education should work to achieve desirable outcomes.

Results: In this study, we collect semi-structured interview data from 23 team members from a total of 4 teams at 3 institutions across the USA. We analyze the results using a grounded theory approach and connect them to the existing literature. This study builds upon the first part of our work that developed a model of team inputs that lead to team outcomes. In this part, we identify the mechanisms by which input characteristics influence teamwork and outcomes. Team member data expand this initial model by identifying key aspects of team processes and emergent states. In this paper, we present five team processes: strategic leadership, egalitarian power dynamics, team member commitment, effective communication, and clear decision-making processes, that shape how teams work together, and three emergent states: shared vision, psychological safety, and team cohesion, that team members perceived as important aspects of how teams feel and think when working together.
\end{abstract}

Conclusions: This work furthers our understanding of how instructional change teams can be successful. However, due to the highly complex nature of teams, further investigation with more teams is required to test and enrich the emerging theory.

Keywords: Instructional change, Teams, Grounded theory, Leadership, Faculty, STEM

\section{Introduction}

About 10 years ago, an advisory group of the nation's leading scientists and engineers released a report emphasizing the need for increased attention to the effectiveness of Science, Technology, Engineering, and Mathematics (STEM) education in the United States (U.S.) (PCAST,

\footnotetext{
*Correspondence: ntiana.sachmpazidi@wmich.edu

${ }^{1}$ Center for Research on Instructional Change in Postsecondary Education, Western Michigan University, 1903 W. Michigan Ave., 49008 Kalamazoo, USA ${ }^{2}$ Mallinson Institute for Science Education, Western Michigan University, 1903 W. Michigan Ave., 49008 Kalamazoo, USA

Full list of author information is available at the end of the article
}

2010). The report advocated for the widespread adoption of new teaching practices that can help increase diversity and graduation rates, as well as help undergraduate students gain a deeper understanding of the subject matter and reach long-term success.

Many past instructional change efforts have focused on supporting individual faculty's adoption or adaptation of these teaching practices (Henderson et al. 2011). There is substantial research on faculty working in groups (e.g., Ward and Selvester (2012); Richlin and Cox (2004); Cox (2001)). For example, faculty learning communities (FLC)

\section{Springer Open}

(c) The Author(s). 2021 Open Access This article is licensed under a Creative Commons Attribution 4.0 International License, which permits use, sharing, adaptation, distribution and reproduction in any medium or format, as long as you give appropriate credit to the original author(s) and the source, provide a link to the Creative Commons licence, and indicate if changes were made. The images or other third party material in this article are included in the article's Creative Commons licence, unless indicated otherwise in a credit line to the material. If material is not included in the article's Creative Commons licence and your intended use is not permitted by statutory regulation or exceeds the permitted use, you will need to obtain permission directly from the copyright holder. To view a copy of this licence, visit http://creativecommons.org/licenses/by/4.0/. 
are a common approach where faculty meet regularly to improve their teaching (Cox 2004) by making use of collegial support (Andrews et al. 2016). FLCs focus on faculty development (Cox 2004), and fall within the reflective teachers' category of Henderson et al.s (2011) framework of change strategies. Faculty in an FLC are encouraged to develop distinct goals for their courses, and share ideas, resources, and information among their groups (Addis et al. 2013). In these ways, FLCs aim to and can be effective at promoting change at the individual level (Cox 2001).

Recently, an increasing number of change researchers have been advocating for systemic approaches to change that can more effectively promote sustained improvements (e.g., Chasteen et al. (2015); Reinholz and Apkarian (2018)), and funding agencies are increasingly supporting projects focused on department- and institutional-level transformation (Weaver et al. 2016). Team-based instructional change efforts to improve undergraduate STEM education are a critical example of a systemically-focused approach (Olmstead et al. 2019; Gast et al. 2017; Weaver et al. 2016). Teams differ from other types of groups because team members work towards a common purpose and are accountable for the team's work (Katzenbach \& Smith 1993). Gilley and Kerno (2010) emphasize the distinction between a group and a team by saying, "all teams are groups, but not all groups are teams" (p. 48). They argue that teams have greater self-management and autonomy levels and are more creative and innovative than groups (Gilley and Kerno 2010). Similarly, Quinn (1995) highlights the differences between a team and a committee in terms of their responsibility, authority, management, objectives, process, and access to information. For example, he argues that teams are formed to work around a subject area and are responsible for taking and executing the decision. On the other hand, committees are formed to accomplish a single task and primarily serve an advisory role without actively participating in the decision-making process.

Team-based instructional change efforts typically involve groups of instructors and other stakeholders who meet regularly and work collaboratively to improve existing courses and/or create new courses within a department or an institution. These team-based approaches have the potential to facilitate coherence across a series of courses and/or over multiple semesters better than approaches focused on individual instructors (e.g., Chasteen et al. (2011)). But to date, there has been limited research on such teams in the context of higher education (Gast et al. 2017; Henderson et al. 2011).

There is extensive research on teams in non-higher education contexts such as business management (Guzzo and Dickson 1996; Ilgen et al. 2005), and healthcare (Leggat 2007). This work has demonstrated that teams can perform better than individuals on a wide variety of complex tasks (Woolley et al. 2010). Similarly, in the context of higher education, Wunchy, Jones, \& Uzzi (2007) found that teamwork is prevalent in scholarly work across all fields of research and that teams typically perform better than individuals. For example, they note that papers with multiple authors are cited more often than papers by solo authors. However, teams are not always successful (Karlgaard and Malone 2015; Mannix and Neale 2005). They face many potential failure points such as communication challenges (Karlgaard and Malone 2015; Fiore 2007; Stasser et al. 2000) and interpersonal conflicts (Jehn et al. 1999; Lau and Murnighan 1998; Mannix and Neale 2005) that can result in a significant waste of time, money, and goodwill.

Although existing literature may provide some insights about what leads to team success, it is unclear to what extent findings from other contexts are applicable in the context of instructional change in higher education. Distinctive features of this context in higher education suggest the need to develop a distinctive approach to change within this context (Kezar, 2001). Some instructional change researchers (e.g., Corbo et al. (2016); Kezar and Gehrke (2015); Reinholz and Apkarian (2018)) argue that results from business management can provide useful insights, but only after adaption to the context of higher education. We agree with this stance. Thus, in this study, we focus on instructional change teams in STEM higher education and seek to identify context-specific practices and conditions that lead to favorable outcomes. Our focus on the STEM disciplines is due to the national attention towards STEM degree attainment. However, findings from this work might translate into other disciplinary instructional contexts.

Our long-term goal is to provide a comprehensive view of the nature of instructional change team collaboration in the context of undergraduate STEM. This study is the second phase of a larger exploratory project. In the first phase of the study, Olmstead et al. (2019) assembled a tentative model of how instructional change teams work together to produce various outcomes. Olmstead et al. (2019) identified key team input characteristics and proposed key elements of team outcomes based on interviews with project leaders. The five-team inputs that describe how these teams are set up include the nature of the task, who participates, process constraints, external engagement, and access to resources. The four types of outcomes important for these teams are the sustainability of instructional changes, quality of the instructional changes, changes in team members' collaboration, and changes for individual team members. Olmstead et al.s (2019) model align with Marks, Mathieu, \& Zaccaro's (2001) claim that team processes (what teams do) and emergent states (what teams feel and think) mediate the relationship between the inputs and outcomes. In this second part of the study, we 
continue to build on this model by unpacking the contextspecific team processes and emergent states. Hence, in this paper, we address the following research question:

What are specific team processes and emergent states that shape instructional change teams' collaboration and can lead to favorable team outcomes?

\section{Methods \\ Methodology}

Because there is so little existing literature about instructional change teams, our work is exploratory by nature. As such, we use grounded theory methodology to guide the study design and data analysis (Becker 1993; Gibson and Hartman 2013). The most prominent characteristic of this methodology is the openness to ideas that emerge from the data. This protects theory-building from becoming dampened. When building a grounded theory, researchers avoid reading or drawing on any pre-existing ideas from the literature until they have identified the main emerging ideas in the data (Gibson and Hartman 2013). A grounded theory often centers on a core category that is "the integrating idea for the theory" (Gibson \& Hartman, 2013, p.39).

Our long-term goal is to conceptualize the relationships among a set of variables relevant for instructional change teams and identify those variables that are primarily responsible for the variation in team outcomes. We are approaching this goal in three phases. These three phases make up the broader study. Consistent with a grounded theory approach, at the end of each phase of our analysis, we review the literature to enrich the interpretation of our findings and illustrate connections to existing ideas. In the following paragraphs, we present the steps taken to use grounded theory to reach our expanded model on instructional change teams. Figure 1 presents the summary of the three phases of this broader study on instructional change teams.

Phase 1: During the first phase of this study, we laid the groundwork for the nature of instructional change teams' collaboration. This phase was based on interviews with leaders of team-based instructional change projects at higher education institutions across the U.S. (Olmstead et al. 2019). We identified five-team setup characteristics: nature of the task, who participates, process constraints, external engagement, and access to resources, that describe how these teams are set up, and four outcomes that are important for these teams: quality of instructional changes, sustainability of instructional changes, individual changes, and collaboration changes. We also found two mediating categories between the team setup charac-

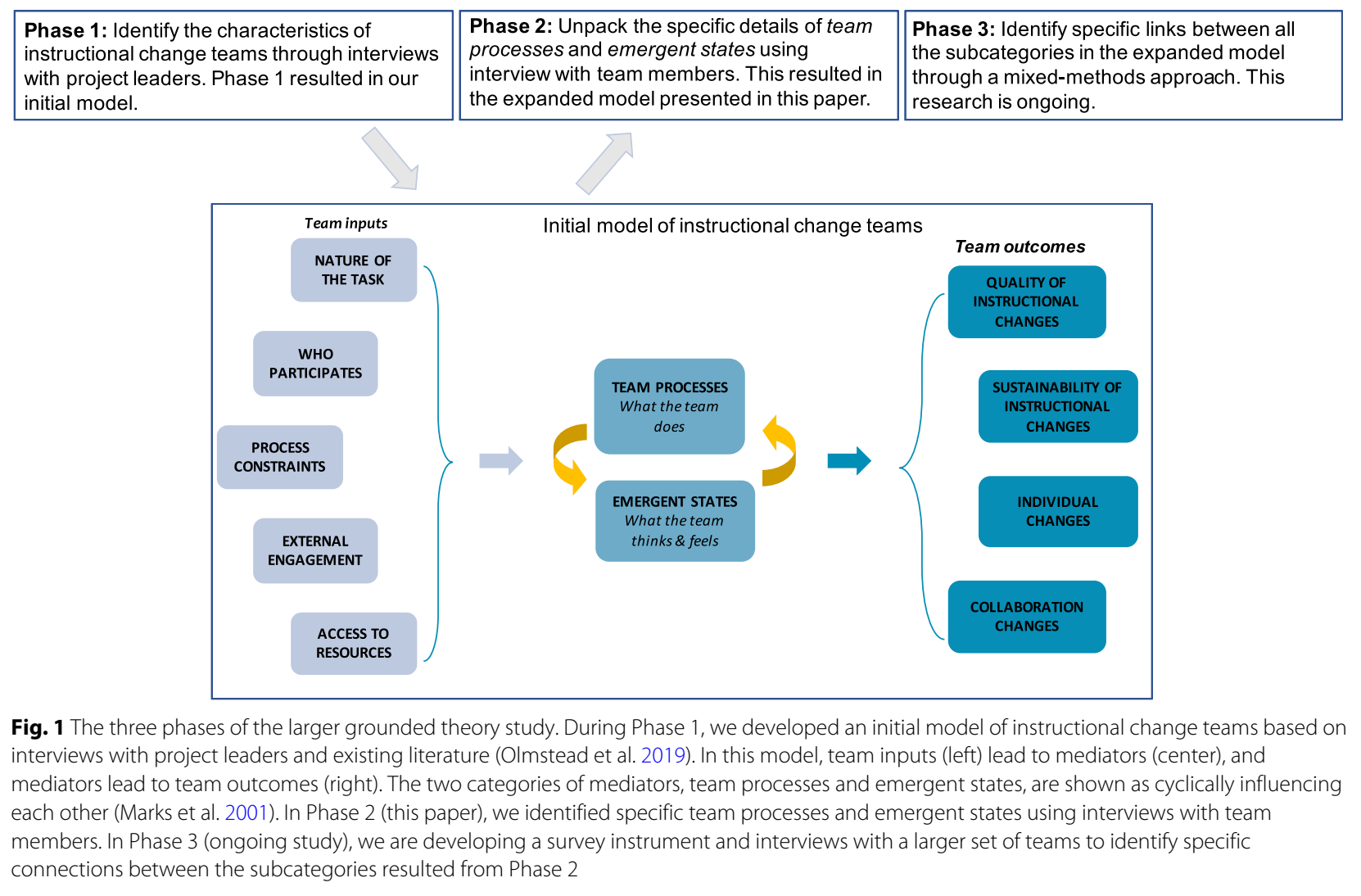


teristics and team outcomes of what the team does and what the team feels and thinks. Consistent with grounded theory, we used the literature as additional data during the late stages of our analysis. We found that our initial emerging model resonated well with literature on teams in other contexts (e.g., Marks et al. (2001)). Specifically, the inputs-processes-outputs (I-P-O) model is frequently used in the teams' literature. We adapted the formal language from the I-P-O model to describe our categories. For example, our "team setup characteristics" became "team inputs," our "what the team does" became "team processes," and finally, our "what the team feels and thinks" became "emergent states." Olmstead et al's (2019) model also incorporates Marks et al.s (2001) claim that team processes and emergent states cyclically influence each other. Olmstead et al. (2019) identified team collaboration, broken into team processes and the emergent states, as the core category (or categories) of our grounded theory.

Phase 2: In this second phase of the study (this paper), we continue to build on this grounded theory by unpacking specific aspects of team collaboration that are linked to team outcomes. More specifically, we aim to identify the subcategories of team processes and emergent states in this initial model that resulted in phase 1 . Using individual interviews with team members allows us to explore team members' perspectives on the nature of their teams' collaboration. Hence in this paper, we investigate the specific aspects of the team processes and emergent states that are responsible for team outcomes and present the expanded model of instructional change teams.

Phase 3: After developing the expanded model of instructional change teams, we aim to focus on the relationship between the (sub)categories on our expanded model from phase 2. In particular, we intend to develop a survey instrument and use a mixed-methods approach of additional data with team members to identify which subcategories of the team inputs, processes, and emergent states, and to what degree, influence favorable team outcomes. This work is currently under development.

\section{Participants and data collection}

In the first phase of this study, Olmstead et al. (2019) conducted semi-structured interviews with the leaders of team-based instructional change projects at 28 institutions across the U.S., eliciting information about their team characteristics and goals. To serve the goal of the second phase of our study, that is to unpack the team processes and the emergent states, we decided to reach out to team members to get their perspectives on their collaboration.

During the first phase of this study, project leaders were asked whether they would be interested in further cooperation at a later stage. Using this information, we followed a theoretical sampling method by approaching each team one at a time, starting from those teams whose project leaders were more eager to continue working with us. We contacted project leaders and requested team members' contact information. In this study, we consider someone to be a team member only if the project leader (or the team members) identifies them as one. As we describe later, all team members had roles (either well- or ill-defined) that defined their team membership. We invited all the team members to participate in an individual 30-60-minute phone or video interview.

Our final sample consisted of thirty-two team members from six teams at five institutions (one institution included two teams). Five teams in our dataset were situated within single departments; one team spanned multiple departments. We only included teams that fit our definition of a team-three or more individuals that meet regularly to work together on instructional change by either revising existing course(s) or creating a new course(s) within a department or an institution-and those for whom we have interview data from three or more team members who actively participate in the team's meetings. Two of the six teams for which we had collected data did not meet at least one of the two criteria. Twenty-three team members from the remaining four teams operated within single departments. These teams are from the departments of biology $(n=8)$, physics $(n=4)$, material science $(n=6)$, and engineering $(n=5)$. All the teams in our dataset belong to research-intensive institutions. For our analysis, we assigned pseudonyms to identify individual team members.

Data were collected through in-depth, semi-structured interviews (see Additional file 1 for the interview questions). The interviews were transcribed verbatim. Participants were also asked to provide their demographic information through a short online survey. Table 1 displays the total number of participants, the goal the team was formed to achieve, and the demographics of the interviewees of each team.

\section{Teams' overview: inputs and outcomes}

Besides using project leaders' interview data, we also elicited team members' perspectives about the five team inputs and four outcomes identified in the first part of our work (Olmstead et al. 2019). These team inputs are: nature of the task, who participates, process constraints, external engagement, and access to resources. The four team outcomes are as follows: sustainability of the instructional changes, quality of the instructional changes, collaboration changes, and individual changes. We rely on team members' perspectives and the extent to which we find agreement across team members to assess these outcomes. Table 2 summarizes team members' responses on achieving each team outcome. 
Table 1 Information about teams and team member interviewees

\begin{tabular}{|c|c|c|c|c|c|c|}
\hline $\begin{array}{l}\text { Team or } \\
\text { department }\end{array}$ & $\begin{array}{l}\text { Lifetime } \\
\text { (years) }\end{array}$ & $\begin{array}{l}\text { Team } \\
\text { size }\end{array}$ & $\begin{array}{l}\text { Number of } \\
\text { participants }\end{array}$ & Goal & $\begin{array}{l}\text { Diversity/demographics } \\
\text { of interviewees }\end{array}$ & $\begin{array}{l}\text { Team members' } \\
\text { pseudonyms }\end{array}$ \\
\hline \multirow[t]{6}{*}{ Physics } & 4 & 9 & 4 & $\begin{array}{l}\text { Revise and improve } \\
\text { the }\end{array}$ & Race/ethnicity: 3 White, & Jack, Nick, Tanya, \\
\hline & & & & introductory physics & $\begin{array}{l}1 \text { Middle Eastern - } \\
\text { Gender: }\end{array}$ & Hannah \\
\hline & & & & $\begin{array}{l}\text { courses for life } \\
\text { science majors. }\end{array}$ & $\begin{array}{l}2 \text { women, } 2 \text { men - Rank: } \\
2 \text { tenured/ }\end{array}$ & \\
\hline & & & & & $\begin{array}{l}\text { tenure-track faculty, } 1 \\
\text { graduate }\end{array}$ & \\
\hline & & & & & $\begin{array}{l}\text { student, and } 1 \text { teaching } \\
\text { and }\end{array}$ & \\
\hline & & & & & learning administrator. & \\
\hline \multirow[t]{3}{*}{ Material Science } & 4 & 9 & 6 & $\begin{array}{l}\text { Embody computation } \\
\text { within }\end{array}$ & $\begin{array}{l}\text { Race/ethnicity: } 6 \text { White. - } \\
\text { Gender: }\end{array}$ & Austin, George, Mary, \\
\hline & & & & $\begin{array}{l}\text { required } \\
\text { undergraduate } \\
\text { courses in }\end{array}$ & $\begin{array}{l}2 \text { women and four men. } \\
\text { - Rank: } 6\end{array}$ & Jason, Marcos, Anne \\
\hline & & & & the course sequence. & $\begin{array}{l}\text { tenured/tenure-track } \\
\text { faculty. }\end{array}$ & \\
\hline \multirow[t]{7}{*}{ Biology } & 3 & 9 & 8 & Revise the series of & $\begin{array}{l}\text { Race/ethnicity: } 5 \text { White, } 2 \\
\text { Asian, }\end{array}$ & Vicky, Brandy, Cassandra, \\
\hline & & & & $\begin{array}{l}\text { seven introductory } \\
\text { biology courses. }\end{array}$ & $\begin{array}{l}\text { and } 1 \text { biracial. - Gender: } \\
3 \text { women }\end{array}$ & Drek, Richard, Geoffrey, \\
\hline & & & & & $\begin{array}{l}\text { and } 4 \text { men. — Rank: } 4 \\
\text { tenured/tenure-track }\end{array}$ & Andrea, Scott \\
\hline & & & & & $\begin{array}{l}\text { faculty, } 1 \text { non-tenure-track } \\
\text { faculty, }\end{array}$ & \\
\hline & & & & & $\begin{array}{l}1 \text { graduate student, } 1 \\
\text { postdoctoral researcher, }\end{array}$ & \\
\hline & & & & & and 1 tenure-track & \\
\hline & & & & & $\begin{array}{l}\text { undergraduate experience } \\
\text { coordinator. }\end{array}$ & \\
\hline \multirow[t]{6}{*}{ Engineering } & 6 & $8-10$ & 5 & $\begin{array}{l}\text { Add active learning } \\
\text { elements }\end{array}$ & $\begin{array}{l}\text { Race/ethnicity: } 2 \text { White, } 1 \\
\text { Asian, }\end{array}$ & Marcos, Gabriel, Allison, \\
\hline & & & & $\begin{array}{l}\text { into the large } \\
\text { introductory course }\end{array}$ & $\begin{array}{l}\text { and } 1 \text { Hispanic/Latino. - } \\
\text { Gender: }\end{array}$ & Daniel, Chris, (Thanos), \\
\hline & & & & $\begin{array}{l}\text { to increase student } \\
\text { engagement. }\end{array}$ & $\begin{array}{l}1 \text { woman and } 3 \text { men. - } \\
\text { Rank: }\end{array}$ & (Ross) \\
\hline & & & & & $\begin{array}{l}3 \text { tenured/tenure-track } \\
\text { faculty, }\end{array}$ & \\
\hline & & & & & $\begin{array}{l}\text { and } 1 \text { postdoctoral } \\
\text { researcher ( } 1 \text { interviewee }\end{array}$ & \\
\hline & & & & & $\begin{array}{l}\text { did not compete the } \\
\text { survey). }\end{array}$ & \\
\hline
\end{tabular}

This is a description of the four teams that are included in this paper. Sample size refers to the number of interviewees from each team. The demographic information refers only to the interviewees. This information was obtained from a short survey sent immediately after each interview.

Here, we describe the team inputs (left side of the model) and team outcomes (right side of the model), so that the results are only focused on the team processes and emergent states (center part of the model) as shown in Fig. 1 (phase 2). Our dataset includes four teams from departments of physics (which we refer to as the Physics team), material science (the Material Science team), biology (the Biology team), and engineering (the Engineering team). The Material Science and Engineering teams belong at the same institution and are part of a large project focused on instructional change. (See Additional file 2 for team inputs.) 
Table 2 Results on team members' responses on achieving each team outcome

\begin{tabular}{lllllll}
\hline & Physics & Material Science & Biology & Engineering-I & Engineering-II & Engineering-III \\
\hline Quality of instructional changes & + & + & $\bigotimes$ & - & + & \\
Sustainability of instructional changes & + & + & + & + & + & + \\
Individual changes & + & + & + & - & + & + \\
Collaboration changes & + & + & + & - & + & $\bigotimes$ \\
\hline
\end{tabular}

$(+)$ and $(-)$ indicate that team members' perspectives agree on positive or negative outcomes, respectively. Positive outcomes mean that (i) the team has achieved or is making good progress towards its initially desired goals (quality of instructional changes), (ii) keeps meeting to sustain the instructional changes or plans to keep meeting to achieve new goals (sustainability of instructional changes), (iii) team members have personally benefited from their participation in the team (individual changes), and (iv) team's ability to collaborate has improved (or remained optimal) and capacity of teams member to collaborate in the future (collaboration changes). Also, ( $\bigotimes$ ) indicates misalignment in team members' perspectives with respect to the above outcomes.

\section{Physics team overview}

The vice-chair of a physics department (pseudonym "Jack") formed the Physics team after being asked by the deans of the physical and life sciences to improve the introductory physics courses for undergraduate life science majors. The deans' request for change was vague and the specific goals were to be determined by the team. Jack brought together tenured and non-tenured faculty, an administrator who focused on teaching and learning, and multiple graduate students to form a team. The team has been actively working together for four years with Jack as the team leader. All team members report positive outcomes from the team's work. All the team members agree that they plan to keep meeting even after Jack retires and point out that there has been a smooth transition of power towards other team members when needed.

\section{Biology team overview}

The initial goals for the Biology team emerged after several members of an undergraduate curriculum committee in a biology department attended a series of workshops at a center for teaching and learning within their institution. During these workshops, these faculty identified a need to transform the introductory biology courses to use a more student-centered and practice-based approach. Their discussions lasted for several years without much progress towards enacting change in the classroom. The undergraduate curriculum committee decided to advocate for hiring someone who would be responsible for forming and leading a team in pursuing their goals, and the department ultimately hired a biology education specialist (Vicky) for this purpose. Vicky brought together instructors of the courses that were about to undergo revision and courses that are planned to be revised in the future to form a team. She made a detailed plan with specific goals, including suggestions for further changes (and for more courses) beyond those already identified. The team has implemented the first round of changes, which incurred negative student feedback including several student complaints made to the department leadership. The team stayed together and plans to continue working together, although some team members feel uneasy about implementing the changes themselves.

\section{Material Science team overview}

The Material Science team formed when a tenured faculty member (Austin) in a material science department decided to respond to an internal call for course redesign proposals. This call for proposals was part of a broader instructional change initiative in the College of Engineering. Austin was one of the three computational research faculty in his department and approached the other two faculty (George and Mary) to solicit their interest in working together to incorporate computational modules across the curriculum. As the three of them started to form a team, they invited another faculty member (Jason) to join them, and the four co-wrote the proposal. Austin, George, Mary, and Jason now self-identify as the core team. They had pre-existing friendly relationships and identified their team's goals during the proposal-writing phase. Once the team received the funding, they were assigned an experienced team mentor (Marcos) who was already serving as the leader of the Engineering team (below), and were required to meet weekly. The team has now been working together for four years, five additional members have joined the team, and they have focused on eight courses. Most of the new team members are junior faculty in the department. Team members report that they have achieved their initially desired goals, and the team still meets weekly to sustain the instructional changes.

\section{Engineering team overview}

The initial leader of the Engineering team (Thanos) brought together a group of four engineering faculty (including himself) to write an internal course redesign proposal and form a team. The goal of the Engineering team was to add active learning elements into their large introductory course to increase student engagement. The Engineering team is situated in the same institution as the Material Science team and was responding to the same internal call for proposals from the College of Engineering's initiative (in a different department and in an earlier year). During the proposal writing phase, Thanos and 
his colleagues established the goals. This proposal-writing phase lasted for about a year. After the team received the funding, Thanos gradually stepped down from his leadership role and left the team for reasons unknown to the other team members. Another team member (Marcos) organically emerged as the new team leader during the second year of the project: he led the meetings when Thanos did not attend and eventually became recognized as the leader. The Engineering team's composition varied over time in other ways as well, which seemed to have a strong influence on their collaboration and outcomes. We, therefore, describe the Engineering team's collaboration in three distinct phases. The team initially included the four team members mentioned above, who were all tenured/tenure-track faculty and joined based on their interest in the team's purpose, and a lecturer (Ross) who was one of the instructors of the focal course (phase I). Ross was a member on the team for a short amount of time of the team's history. Ross was highly resistant to changing the existing courses. During that time, the team did not make significant progress towards their goals and the team members were ready to disband. After about a year, Ross was removed from the team (phase II). Team members report that the team's collaboration improved significantly and that they achieved initial goals. Later on, instructors whom the department chair assigned to teach the courses under revision also joined the team (phase III). All instructors of those courses were expected to participate in the team, joining the senior team members. During this phase, the team felt they had reached their initially desired goals and generated new goals to further improve the large introductory courses. However, some team members report confusion about what these new goals are.

These teams share (to a greater or lesser extent) specific features that distinguish them from groups or committees (Quinn 1995). For example, all four teams were formed to work around a subject area, specify their goals/objectives, and create and implement the instructional changes.

\section{Analytical approach}

Olmstead et al. (2019) identified two core categories in our instructional change teams model: team processes and emergent states. In this work, we aimed to identify the subcategories for each. We treated each team as one unit of analysis by first collecting data from all the team members who were willing to be interviewed. Once we collected data from all the team members within a team, we started the iterative process of analysis by coding, memoing, and identifying emerging subcategories of team processes and emergent states for that team. This approach helped us better understand team dynamics and capture the different perspectives that each member brings for their team. More specifically, starting with open coding, we analyzed the transcripts line-by-line, identifying the main ideas of team processes and emergent states, while also constantly comparing the emerging ideas across the data to identify similar patterns. In the next stage of the analytical procedure, we used axial coding to identify the inter-relationships of the subcategories to one another and the team outcomes. Thus, we include the specific team processes and emergent states that seemed to influence either directly or indirectly the team outcomes. We continued revisiting the analysis of prior teams to identify similarities when new team data provided further insights into the emerging ideas. Although each team had unique dynamics, we decided to end data collection because we identified several common underlying ideas across the four teams we studied.

\section{Positionality and data trustworthiness}

Grounded theory is characterized by theoretical sensitivity, suggesting that the researchers approach the phenomenon under study having as few pre-conceived notions as possible. Preconceptions could be created either through the exposure to the literature or through professional and personal experiences. The essence of using grounded theory is that the theory arises through the data and is not being affected by information external to the data (Glazer 1978). As researchers living in an academic environment, it was impossible to avoid preconceptions about a phenomenon that takes place within an academic environment, while already having personal experiences by serving in similar instructional change teams within our institutions. Moreover, the senior researchers of the study were familiar with the existing literature.

The first author (doctoral student) worked heavily on the data analysis while the second author provided feedback throughout. The two other senior co-authors provided feedback on the findings and interpretations. As a further validity check, an undergraduate researcher worked independently on some transcripts and found similar results. In approaching the theoretical sensitivity (Glazer 1978), the two researchers that were more involved in the analysis were the ones with the least familiarity with the academic environment and the prior literature. In fact, in many stages of the data analysis the first author felt that she was surprised by the nature of the interactions between faculty in academia (e.g., power dynamics at departments between faculty of varying levels of rank), something that reflects that preconceptions were challenged by the data and that the first author was open to new ideas.

\section{Results}

We identified five team processes and three emergent states that encompass key aspects of how these instructional change teams work together. The team processes 
we identified are: strategic leadership, egalitarian power dynamics, team member commitment, effective communication, and clear decision-making processes. The emergent states we identified are: shared vision, psychological safety, and team cohesion. Each of these is intended to represent a factor that contributes positively to team outcomes. Each team process describes interdependent acts related to the team's task (what teams do), while the three emergent states describe team cognitive, motivational, and affective states (how teams feel and think). The expanded instructional change teams model that includes these findings is shown in Fig. 2, while Table 3 describes the definitions of these mediating subcategories in our model. In this paper, we focus on the strongest connections between the constructs that were identified on more than two teams. However, we saw hints that more nuanced connections might exist. Our current model (as shown in Fig. 2) presents the links in a simplified way. We aim to further investigate the links across all the constructs on the expanded model on the next phase of this study.

In the following subsections, we define each construct, describe what we consider as evidence for that construct, present findings from teams, and draw connections between the constructs on the model. Working backwards from the team outcomes, in the following paragraphs, we first describe the three emergent states. We find that these emergent states most closely relate to the team outcomes and the variations in these outcomes across teams. Next, we consider the four team processes that contributed to the emergent states directly (through close influence on these states). Finally, we consider the team process of strategic leadership that contributed to the emergent states indirectly, through its direct influence on other team processes.

\section{Emergent states}

Emergent states are a core category in our model that refers to team cognitive, motivational, and affective states of how teams feel and think about their collaboration (Olmstead et al. 2019; Marks et al. 2001). We find that the following subcategories of emergent states seem to contribute to desirable team outcomes: shared vision, psychological safety, and team cohesion. Below, we elaborate on the meaning of each subcategory and show evidence for connections to positive team outcomes.

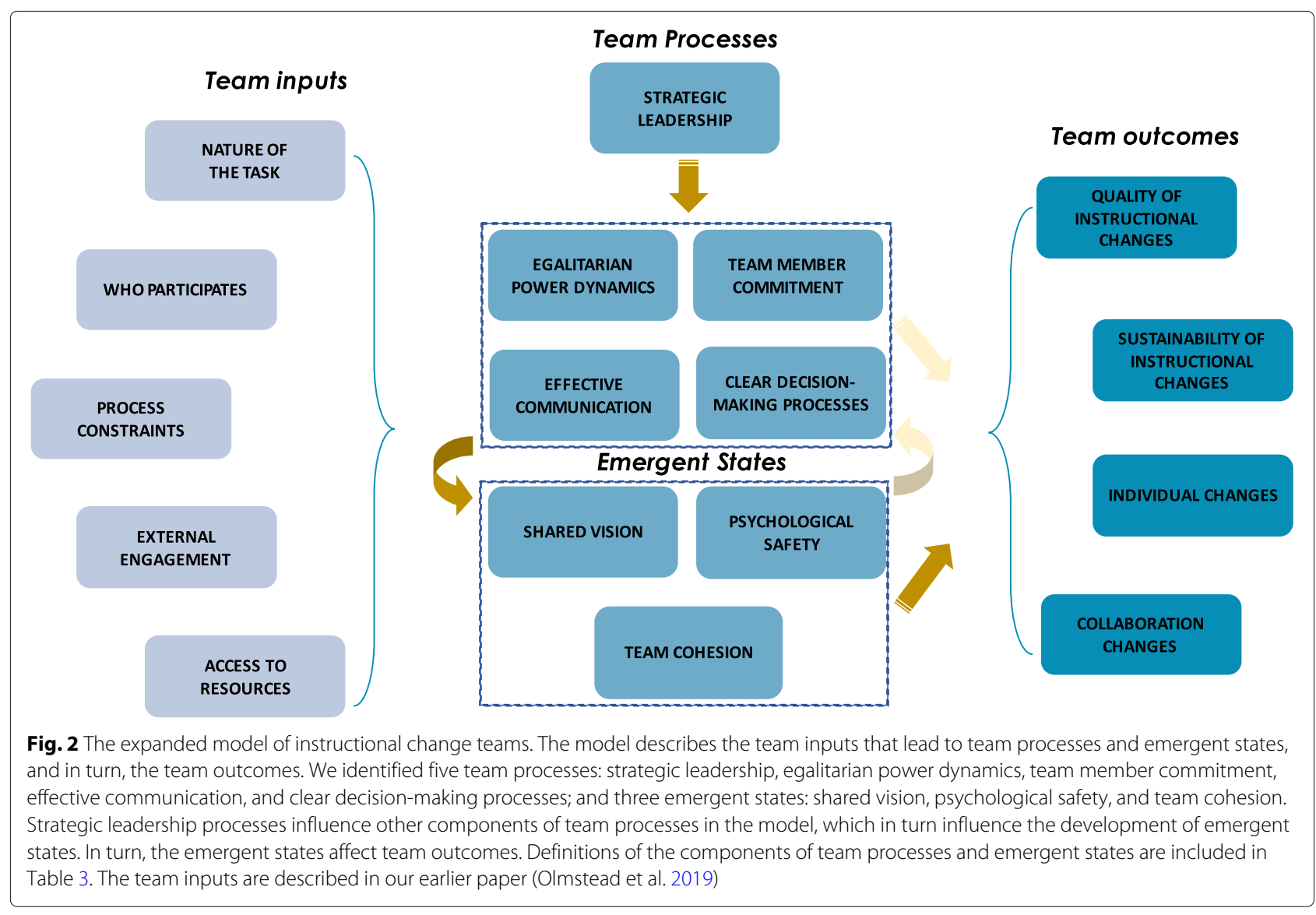


Table 3 Definitions of the subcategories of team processes and emergent states

\begin{tabular}{|c|c|}
\hline Core categories and subcategories & Definitions \\
\hline Team processes & $\begin{array}{l}\text { Team members' interdependent } \\
\text { acts related to the team's task } \\
\text { (Marks et al. 2001). }\end{array}$ \\
\hline \multirow[t]{2}{*}{ Strategic leadership } & $\begin{array}{l}\text { One or more team members } \\
\text { engages in problem-solving related } \\
\text { to the team processes/goals, }\end{array}$ \\
\hline & $\begin{array}{l}\text { build consensus within the team, } \\
\text { and identifies long-term } \\
\text { opportunities and threats. }\end{array}$ \\
\hline \multirow[t]{2}{*}{ Egalitarian power dynamics } & $\begin{array}{l}\text { Team members welcome, value } \\
\text { and consider everyone's } \\
\text { contributions appropriately } \\
\text { regardless }\end{array}$ \\
\hline & $\begin{array}{l}\text { of their personal characteristics, } \\
\text { position in the institution, or role } \\
\text { on the team. }\end{array}$ \\
\hline Team member commitment & $\begin{array}{l}\text { Team members demonstrate high } \\
\text { levels of engagement and interest } \\
\text { in the team's task. }\end{array}$ \\
\hline \multirow[t]{2}{*}{ Effective communication } & $\begin{array}{l}\text { Team members share information } \\
\text { freely, openly discuss and work } \\
\text { through conflicts, and adapt }\end{array}$ \\
\hline & $\begin{array}{l}\text { their communication style so that } \\
\text { others can understand them. }\end{array}$ \\
\hline \multirow[t]{2}{*}{ Clear decision-making processes } & $\begin{array}{l}\text { Team members discuss and agree } \\
\text { on how to go about making } \\
\text { decisions relevant to the team }\end{array}$ \\
\hline & and the team's work. \\
\hline Emergent states & $\begin{array}{l}\text { Team members' cognitive, } \\
\text { motivational, and affective states } \\
\text { (Marks et al. 2001) }\end{array}$ \\
\hline \multirow[t]{2}{*}{ Shared vision } & $\begin{array}{l}\text { State in which team members have } \\
\text { shared understanding and } \\
\text { agreement with the team's }\end{array}$ \\
\hline & goals and ways to reach those. \\
\hline \multirow[t]{2}{*}{ Psychological safety } & $\begin{array}{l}\text { State in which team members feel } \\
\text { that sharing their opinions and } \\
\text { actions on the team will }\end{array}$ \\
\hline & not pose any professional risk. \\
\hline \multirow[t]{2}{*}{ Team cohesion } & $\begin{array}{l}\text { State in which team members have } \\
\text { strong interpersonal connections } \\
\text { and share a sense of }\end{array}$ \\
\hline & accountability to the team's goals. \\
\hline
\end{tabular}

\section{Shared vision}

The term shared vision has been widely used in the literature on teams to describe a collective understanding of a team's goal and mission (e.g., Katzenbach and Smith (1993); Kozlowski and Ilgen (2006)). In this study, we use this term to refer to the state in which team members understand and agree about the team's goals and the ways to reach those. Team members often use the phrase "everyone is on the same page" and similar variations to describe what we see as a shared vision or a lack of shared vision.

The Physics and Material Science teams developed a shared vision over the team's task and the ways to reach those goals. The Biology team had a shared vision about the team's goals, but they struggled to develop a shared understanding of the ways to reach them. Finally, shared vision in the Engineering team was heavily influenced by the team composition that varied by semester.

The Physics team presents an example of a team that established a shared vision. For example, Physics team leader, Jack, states: "I met with the whole bunch of them (faculty at the department) and [the other team members] said, 'You talk. It's fine.' Because we're all on the same page."

Here, Jack describes how his co-team members expressed that he could represent the whole team in communicating the team's work to the department because of their shared vision. Nick supports Jack's claim about the Physics team's shared vision when he contrasts the shared values and goals of the team to the potentially more diverse goals of the rest of his department:

The more difficult and interesting dynamic is the team itself interacting with the department as a whole, because those who were not involved in this process may not really understand what the values and goals are that were built [...] and may not share the same values as the people who are in the team. [...] This all pertains to the actual teaching of the series as opposed to just, for example, planning for the teaching of a new series. That's I think a real difference is that there's actually kind of like a team-teaching mentality as opposed to just like a team planning for possible eventual team teaching.

Nick's use of the phrase "team-teaching mentality" closely aligns with the idea of shared vision, which he specifically connects to the shared goals and values of the Physics team. As mentioned earlier, the Physics team also reported favorable outcomes overall. They specifically report achieving the outcomes in the sense that they selected a textbook that aligns with the goals of the course and developed a sustainable process for revising the laboratory. Below, Nick describes his understanding of what it means for the team to achieve these goals and the certainty he feels about the progress they have made:

I think right now we're using an optimal textbook. There's very little question about that. For the labs, it's an ongoing process, but in this, we've achieved the goal of having an ongoing sustainable machine that's constantly revising the labs and improving them. [...] My 
goal and I think the goal of the team is more we want to constantly be improving everything to the extent possible and with some sort of coherence.

We also find a shared vision to be important and present on the Material Science team. For example, Austin describes how the Material Science team spent significant time discussing their goals and plans in order to get to their current state of being on the same page: "We were very much on the same page. [...] Yeah, we can use the time together talking about what it was that we wanted to do, and planning things [...]." Similarly, Jason describes how the Material Science team agreed about their goals and how to achieve them: "Yes, I think our team was very uniform with respect to that [having a similar commitment on the goal]. I think everyone was very committed and on the same page [...]"

We also see evidence that shared vision is important through Engineering team members' discussion of their lack of shared vision. Gabriel describes how the Engineering team's frequent changing composition influenced the extent of agreement over and understanding the team goals:

I think, sometimes I feel like we're on the same page. And sometimes some people have different interests [...]. It's kind of hard to say. [...] we have new team members from semester to semester, so sometimes a new team member can come on board being very similar-minded as the current team. But we can also have a new team member that's different in their ideology of what engineering education should look like [...].

As shown above, the extent that the Engineering team shares a collective agreement over the goals is being influenced by a varying team composition. Some new team members bring a personal perspective to the table, which is distinct from the rest of the team. For example, Allison describes how she sees that people's views over the goals of the team and on how the team should work together has changed over time:

I think not really [having consensus on the goals]. I don't think so. [...] I mean, I think what has happened with the team is that certain expectations might have changed over time. So when I came in, I was under the impression that it was, everybody was going to contribute in some way to the development of the project, that you weren't just going to come in as just an instructor and use the material, because there was sort of the sense that [...] this was going to require effort and work, but because we're going to do it as a team and together, that was going to be manageable, and you would have support. That was my initial impression, and since that, that has changed a bit.
Although, the team members agree that the original goals have been achieved, the recent changes to the team composition resulted in a lack of shared vision, which in turn, resulted in confusion in team members' perspectives on what the new team goals are. Daniel, below, mentions:

I would say, yes [on achieving team goals], but I would also say that our goal is, at this point, somewhat fuzzy.

Similarly to the Engineering team, the Biology team developed shared vision on the team goals, but lacked shared vision on how the changes should be implemented. Shared vision over the team's goals helped the team implement the intended goals. However, the lack of clarity over the action steps that the team should follow resulted in varying perspectives among team members on the quality of outcomes, mainly due to negative affective students' reactions to the instruction. For example, some team members mentioned that the team has definitely achieved its goals by saying "Yes. Unqualified, absolutely yes," and others say "We're not quite there yet."

\section{Psychological safety}

We define psychological safety as the state in which team members feel that sharing their opinions and actions in the team will not pose any professional risk. We adopt our definition and terminology from Edmondson (1999), who coined the term "psychological safety" to describe a phenomenon that closely aligns with what we observe on these instructional change teams. We consider team members' statements on feeling comfortable in openly sharing their opinions to be evidence of psychological safety.

All teams we study had developed a sense of psychological safety in voicing their opinions and concerns in the team. The Material Science team easily developed psychological safety in communicating openly and safely. Jason's quote below showcases the aspect of psychological safety on the Material Science team:

That's, for example, one thing that I said previously, that we were all young and kind of at the same rank, but I think that actually helped. I can see that if there was someone very senior, I would be less comfortable expressing my opinion. But because we were all at the same rank, more or less [...] we felt that we could openly talk about everything.

Mary corroborates this argument by saying, "I think it was pretty egalitarian. Everyone, I think, felt free to voice their opinion. [...] It never felt like that it wasn't a democratic process." We also find that the state of psychological safety on the Material Science team contributed to positive changes in the team's ability to work together. For example, Anne, mentions: 
I was so intimidated by the team lead, because he was the most senior faculty on the team, and he was a big personality. I was afraid of him, honestly. [...] But now we're actually good friends and we're writing proposals together, and, quite frankly, I think without this immersive interaction with him, that would have taken a lot longer for me to develop those relationships. So originally, I was afraid to ask him questions about teaching 'cause I thought they were just stupid, and now I realize that we're all in kind of the same boat. So the relationships have changed, I think they've gotten better.

We find that psychological safety captures an important strength of the Engineering team. Allison describes how their team felt able to communicate openly and express themselves within the team:

It definitely felt like what happened in that room stayed in the room, and we were more inclined, yeah, to kind of vent our frustrations or wish, you know, whatever, whether it be with the department or other senior faculty and know that it wasn't going to get around to anyone else. It made communication more open.

This quote provides some insight into the complexity of the Engineering team in both its emergent states and its outcomes. Although the Engineering team struggled, some positive outcomes for individuals did emerge, in part because of this shared feeling of psychological safety.

\section{Team cohesion}

While shared vision refers to the extent to which team members agree on what the goals should be and the ways that the team should achieve them, team cohesion is the state in which team members have a strong interpersonal connection and share a sense of accountability to the team's goals. We consider team members' statements on how positively they feel about working with the rest of the team to be evidence of team cohesion (or lack of). Often such positive statements were attributed to the strong interpersonal connection between them and/or the shared responsibility to accomplish the team goals.

The Physics, Biology, and Material Science teams had a strong and shared commitment to the team's task. The Material Science team exemplifies what team cohesion can look like and how it can contribute to positive team outcomes. It also provides some insight into how team cohesion might develop. The team members that formed the Material Science team were initially friends and were required to meet weekly as a stipulation of the internal funding they received. Because of their preexisting friendships, they decided to meet in an informal setting over lunch. These lunch discussions resulted in team members staying committed to the team's work, participating actively, and continuing to develop positive interpersonal relationships as the team expanded to include new members. Marcos describes the strong social aspect on the Material Science team and how it contributed to the state of team cohesion:

\section{I think one thing that I thought was significant to me with this team was the extent to which [team members] formed friendships from this. I think it was a contributing factor to people getting to know each other socially. [..] I wouldn't say that, that's by any means required for good team functioning, but at least, in the context of this team that did seem to be an important thing that really played into how [team members] interacted. [...] This team blew it over a lot into their both research and personal lives. And so, I think that was part of what made it such a strong team.}

Anne described the state of cohesion on the Material Science team and its relationship to the sustainability of the changes that were implemented:

First of all, we felt, which I didn't really appreciate going in, it's really important to actually have meetings. One of the things we did was to have weekly lunch meetings, whether we liked it or not. So, getting buy-in that way was really important to maintain team cohesion.

Mary also described how the Material Science team keeps meeting weekly to sustain the changes implemented, stating: "Yeah, it keeps going. Every week, we meet every Wednesday. We just finished our meeting today. So yeah, this is just the standard now."

In the Engineering team, we find that lack of team cohesion was evident when team members' expressed their frustration in working on the team. For example, Allison's describes how her feelings on working on the team changed negatively:

I think I've become a little bit more pessimistic about it [working on the team], to some degree.You know, like I'm less inclined now to give it as much energy as I was at the beginning.

As we will see later, Allison described specific aspects of team collaboration that led to lack of team cohesion in the Engineering team.

\section{Team processes}

Team processes is the second core category in our model. They refer to team members' interdependent acts that convert inputs to outcomes through cognitive, verbal, and behavioral activities directed towards organizing taskwork to achieve collective goals (Olmstead et al. 2019; Marks et al. 2001). We identified five subcategories of team processes that seem to positively influence the 
emergent states and ultimately the team outcomes. These are egalitarian power dynamics, team member commitment, effective communication, clear decision-making processes, and strategic leadership. We introduce and discuss each process below and demonstrate evidence of their direct links to the emergent states discussed in the prior section. We also discuss the influence of strategic leadership on other team processes in the model.

\section{Egalitarian power dynamics}

We define egalitarian power dynamics as the process in which team members welcome, value, and consider everyone's contributions appropriately regardless of their characteristics, position in the institution, or role on the team. Several team members mentioned power dynamics between individuals who had a differently-leveled position either on the team or in the department (e.g., junior versus senior faculty; tenured/tenure-track faculty versus non-tenure-track instructors or staff). Team members primarily described egalitarian power dynamics that positively influenced the team and helped them to establish productive emergent states, contrasting this with intrinsic, position-specific hierarchies that could have negatively influenced the team under different circumstances. We consider statements about team members being encouraged to contribute to the team's conversations and being listened to regardless of their position in their team/department to be evidence of egalitarian power dynamics.

We find that all four teams engaged in interactions that fall under egalitarian power dynamics. The Material Science team presents a strong example. Marcos described his perception that all team members' opinions and contributions were welcomed in the Material Science team, stating:

There was no formal distinction in authority, and certainly, nobody had the authority to tell anybody else what to do. [...] I think there was some implicit hierarchy [...], but that was more in the nature of deferring to somebody with more advice or taking advice rather than an authority type of situation.

Anne corroborated this argument by saying, "I feel like no one is monopolizing the conversation, no one is really dictating which directions we're going. And in many cases, our new ideas arise just from these casual conversations that we have over lunch on a weekly basis." Anne also described how her ability to work with these team members has shifted since they started to work together:

I was so intimidated by the team lead, because he was the most senior faculty on the team, and he was a big personality. [...] But now we're actually good friends and we're writing proposals together, and, quite frankly, I think without this immersive interaction with him, that would have taken a lot longer for me to develop those relationships.

As Anne described her experience, we can see that egalitarian power dynamics in the Material Science team helped them to develop psychological safety. Because the team regularly interacted in a friendly and nonjudgmental way, Anne began to feel safe to openly share her opinions, thoughts, and concerns with her senior colleague and the other team members.

The Physics team also demonstrates egalitarian power dynamics that are seen as favorable by team members. While team members respect Jack's role as the team leader and notice that he has authority in their department, they also described how Jack has used his role on the team to value and ask for everyone's opinions and contributions regardless of their position in the department. Tanya described this dynamic:

\section{He [Jack] listened to what they [the other team members] wanted and what they thought was important, and he helped find which parts they thought was important that the rest of the group agreed with or was okay with. [...] It's just that I think everybody in the group got to feel listened to and respected in that sense.}

Tanya highlighted how Jack respected and valued every team members' role and opinion on the team by ensuring that each member had opportunities to contribute something they cared about. Jack corroborated Tanya's description and describes how it aligns with his intended approach: "[...] and so it was possible for everybody to speak their mind without anybody getting angry because they knew that I had made it clear that everybody was to listen to everybody."

Consistent with the above statements, team members described how the team leader delegated responsibility for the lab revisions to a graduate student team member, and the team respected her actions and decisions around that task. This respect for lower-ranking team members is again consistent with egalitarian power dynamics. The process of egalitarian power dynamics also helped the Physics team develop a sense of psychological safety in openly voicing their opinions and concerns.

We also find that an egalitarian approach characterized teamwork in Biology and Engineering teams. Team members in both teams mentioned that everyone's opinions were heard and shaped the overall ideas on the table. Brandy, a graduate student on the Biology team, described this aspect of egalitarianism on her team:

People have good discussions, definitely not just shutting anyone down, letting everyone have a say. I think there have been some really interesting discussions that have stemmed from our meetings as far as new 
ideas or different thoughts, that one person hadn't thought of that angle, so then it makes it interesting to hear both sides of the story of how maybe we could meet a goal. [...] It's been really useful to bounce ideas off of each other, just that collaborative talk.

Similarly, Daniel, on the Engineering team, described that although Marcos oversees the project and leads the team, all the team members have contributed to the team's ideas and goals equally. His quote below showcases this aspect:

I will say that Marcos is the PI for the team, and so it is largely his vision that has driven this whole project. However, I don't want to say that he's the sole person responsible for the team's goals. However, frankly he's led a very open team setup where really anybody can feel free to make suggestions. [...] While Marcos is the PI I think everybody on the team feels as though they're kind of an equal contributor and, as I said, he's been quite supportive.

\section{Team member commitment}

We define team member commitment as the process by which team members demonstrate high levels of engagement and interest in the team's task. We consider statements about team members playing an active role on the team by taking up tasks and responsibilities related to the team's goals to be evidence of team member commitment. This can include participating in meetings with team members or people outside the team regarding the team's work, as well as actions taken regarding the team's task.

We find that strong team member commitment positively influenced the Material Science, Physics, and Biology teams, while different levels of team member commitment (including active disinterest by one team member) often presented a challenge for the Engineering team and negatively influenced their work. The Physics team had a strong team member commitment. Several team members describe how each team member had a role (which was not well-defined) and tasks they needed to accomplish. Team members would select the roles that they wanted to serve according to their interests. A quote from Tanya described this aspect of the team's collaboration:

The roles were kind of what we were each excited about and then we would take that on. [...] I think in a way that was a strength of this team compared to other teams I've gone to. Nobody got assigned to do something they didn't want to do. They just did the things they were excited about and then Jack [team leader] would help incorporate those into the course.

The above quote shows that team members had an interest in the team's tasks and were willing to take up responsibilities. Moreover, a graduate student member, Hannah, described the roles of several team members and ends up by saying:

\section{There were no professors or staff members who were there who were not directly involved in some way.}

The Material Science team provided evidence of what a strong team member commitment can look like. For example, we see that there were team members who remained part of the Material Science team by participating in the weekly meetings even during the semesters that they were not teaching the courses under revision. All the members of the Material Science team whom we interviewed agreed that everyone on the team demonstrated a strong commitment to the team's task by regularly participating in team meetings. Mary described how team members' contribution heavily relied on their expertise. She particularly mentioned that team members would take up responsibilities if they deemed that they could be useful. She also referred to the team's positive interpersonal relationships which helped team members take actions to contribute to the team's work:

\section{If there needed to be something to do with molecular dynamics, that's my expertise. I would help take the lead on that module. If it was something on quantum chemistry, Austin is an expert in that. So he would do that. I think the team was small enough that worked well, and we had a good working relationship that people were willing to chip in where they saw that they could be useful.}

We see the Material Science team's high level of commitment contributing to and being reinforced by positive emergent states like their strong team cohesion.

The Engineering team provides evidence that a lack of team member commitment can negatively impact a team. As described earlier, the Engineering team initially included the four team members who initiated the team and a lecturer, Ross, who became involved because of his role as an instructor of a focal course (see §Engineering Team Overview, Phase I). Ross displayed an extreme lack of commitment: he was very reluctant to discuss any changes to the course and opposed to enacting potential changes. There were constant arguments that caused frustration for the rest of the team members. Eventually, this caused the commitment of other team members to decrease, to the point where the team was about to collapse. Marcos described the worsening situation leading up to Ross being removed from the team:

That was very stressful. It was very unpleasant. I think it was basically a situation where we either had to get 
rid of that person or the team was just gonna disintegrate. Nobody wanted to talk about anything because it was just, there were too much disagreement and too much arguing. And so, I think recognizing that and then actually carrying through the change in team membership was really the key.

After Ross was removed from the team, the original team members demonstrated high commitment and recount that they achieved their initially desired goals (phase II). However, as team members changed over time who were assigned to the focal courses by the department chair (and "assigned" to be on the team as well), the team member commitment varied again and created new challenges (phase III). The senior team members we interviewed recall that those new team members were not as involved in the team as they were. Allison described a typical team meeting at this stage and the level of involvement from the senior and incoming team members:

In our case, our team leader [...] would create an agenda, and then some people were quiet and didn't say much. [...] But you know, it was again self-initiated amongst all of us, the degree of discussion. As I said, some people were just pretty quiet and I felt like there because they felt like they had to be there. [...] Since then, you know, there's been different team members that have or have not participated to the degree that I thought we should have all been participating.

In the Engineering team, we observed different levels of team member commitment between the senior and new team members. We observed that having low team member commitment, especially the imbalance in team member commitment between the senior and the new team members, resulted in a lack of team cohesion. Finally, as we discussed earlier, Allison's change in the attitude of working on the team was due to the different levels of engagement of some team members, and that results in a lack of team cohesion among the team as a whole.

\section{Effective communication}

We define effective communication as the process by which team members share information freely, openly discuss and work through conflicts, and adapt their communication styles so that other team members can understand them. We consider team members' statements regarding how openly the team communicates or how the team handles conflicts when they arise to be evidence of effective communication. For example, team members mentioned that the team communicated effectively, such that any disagreements that would come up could quickly be resolved. On the other hand, we consider a lack of effective communication to be evident when team members mentioned that ongoing conflicts were left unresolved due to communication barriers, or an unwillingness to communicate about and try to resolve interpersonal problems among team members.

We find that the Material Science and Physics teams communicated in an open way working through conflicts without imposing changes on anyone; their communication was centered around consensus-building. In the example of the Material Science team, the pre-existing friendly relationships between the team members helped the team develop processes of effective communication in the team. We also see that new members who join the team can be influenced by the pre-existing environment, which Jason referred to as "blending in the spirit of the team:"

The team was built with people that get along, that have some sort of relationship before [...]. Of course, that doesn't mean that only teams with best friends can function, but we knew how to communicate with each other before we were a team. And I think that was important. And even when we add new members, they're just new, they sort of blend in the spirit of the team. Sort of like open communication, and I think that is important.

Effective communication was also important for the development of a shared vision on the Physics team. Jack's description below demonstrated how he would help the Physics team to resolve potential conflicts by leveraging his role as a leader and focusing on communication:

\section{So I had, fortunately, I had everyone's respect. And so, they were listening to what I was saying. They also knew that I was listening to what they were saying. And so, everybody could speak their mind without anybody getting angry because they knew that I had made it clear that everybody was to listen to everybody. [...] We were all going to try and do this better. And so, it was a very gradual non-domination.}

In contrast to the Material Science and Physics teams, the Biology team struggled to communicate effectively, which negatively influenced their team's success. On the Biology team, some team members would propose changes regarding the implementation of specific aspects of the course without explaining the motivation behind their suggestion, revealing evidence of unclear communication. Team members described how they were unconvinced about the necessity of the proposed changes because of this lack of clarity. Cassandra provided an example of such an interaction on the team:

There was one person who felt very strongly something should be shifted into the second semester from the first 
semester, but the rest of us weren't really seeing how that shift would work. [...] There was just some hesitation there. We kinda are going ahead with it anyway. That would be kinda one example where communication maybe wasn't as clear as it could have been. Some of us thought it was going to come up for discussion again but the other person thought it was a closed and done situation.

We find that some team members did not feel comfortable about implementing some of the team changes. Another member of the Biology team mentioned that they had become better in communication over time, implicitly alluding to a previous time when they felt there was a lack of effective communication.

Similarly, we find that a lack of effective communication was evident in the Engineering team. As was mentioned earlier, some team members felt frustrated by the lack of team member commitment from a few team members. However, although those team members stated that the team should talk openly about team membership expectations, this did not happen on this team and neither those concerns were openly discussed among the team members. Moreover, one team member mentioned that there is confusion about the new goals the team is working towards, which also supports the lack of effective communication in the Engineering team.

\section{Clear decision-making processes}

We define clear decision-making processes as the process by which team members discuss and agree on how to go about making decisions relevant to the team and the team's work. We consider statements that team members agree on how and by whom decisions are made to be evidence of the clarity (or lack of clarity) of decision-making.

In all but one teams, team members described the importance of establishing clear decision-making processes. Some teams explicitly discussed these processes, e.g., establishing that instructors had the ultimate say over the ways that they would implement instructional changes. On other teams, decision-making processes emerged organically and were understood by all the team members. For example, the Material Science and Engineering teams explicitly established that individual instructors had the authority to implement changes in any way they wanted to, while the team would reach a consensus on their major goals and recommendations. Jason depicted this process on the Material Science team:

It was always understood that this is your course. You are the instructor. There are no rules or there's nothing that you have to follow, but here are some recommendations that might work for you. I think that tone was crucial for all of us [...]. So, I felt it was very open, non-judgmental and no rules. All this that we are doing are recommendations. But ultimately, it's your course. I felt that was very important.

Similarly, on the Engineering team, several team members emphasized that the instructors had the final say regarding any changes to their courses, showing that a decision-making process was established among all the members. For example, in the following quote, Marcos mentioned that although the team discusses any ideas and that everyone puts in their input on the table, the general agreement is that instructors will make the final decision over their courses:

Yes, so I think you were just saying about the graduate and undergraduate students, [they] had opinions but they didn't really have any decision-making capability. [..] The faculty member still has complete control over their class. Nobody on the team can tell anybody else that they have to do something in their class. They can do anything they want. However, we wouldn't do things without discussing them with the whole team first. So, we would sort of voluntarily discuss ideas, and discuss plans, and when we brought new people onto the team, we would always talk to the person before they joined the team and say, "If you want to join the team, here's, your sort of things." But, formally, at the end of the day, if somebody is teaching a class, they can do whatever they want.

On the other hand, the Physics team organically established that decision-making would revolve around consensus-building. Eventually, if consensus could not be reached, a final decision would be weighted slightly towards opinions that were supported by education researchers and/or experienced practitioners. Tanya described this process:

\section{Jack didn't impose things on people but I would say made decisions based on the person whose opinion he thought was most expert.}

For example, Nick was considered one of the experts in the lecture implementation. Jack would ask Nick what he thought would be best in terms of online homework and various things like that and make decisions.

In contrast, team members' perspectives about decision-making processes varied significantly on the Biology team. Some team members stated that the final decision-making was up to individual instructors (as in the Material Science and Engineering teams), others stated that decisions were weighted towards the opinions of those who are more expert in specific subject matter, and while still others stated that it was more weighted towards the team leader (Vicky) because of her authority in the team and her responsibility for this effort. These 
divergent views on the decision-making process could play a factoring role in the lack of a collective understanding of how the team's goals should be reached. These views also seem to be reflected in the lack of effective communication in the Biology team that was discussed earlier.

\section{Strategic leadership}

We define strategic leadership as the process by which one or more team members engage in problem-solving related to the team processes or goals, builds consensus within the team, and identifies long term opportunities and threats. We consider team members' statements about one or more team members (often the formal team leader) taking action and engaging in problem-solving related to the team's work to be evidence of strategic leadership.

Our data suggest that strategic leadership was present in most of the teams and that it shapes the other processes in our model. The Physics team provides an example of how a team member-in this case, the formal team leader, Jack-can enact strategic leadership by identifying and developing a plan to overcome potential threats to a team's success, and showcases other aspects of strategic leadership such as orchestrating the team meetings in such a way that it is possible to build consensus. In particular, Jack's actions of strategic leadership in identifying the value of building a consensus related to the team's goals and decisions enacted the processes of egalitarian power dynamics, effective communication, and clarity over decision-making. When the team's interactions revolve around consensus building, all team members' opinions and concerns are taken into account and shape the final decision (e.g., vs. majority vote). In this way, we see that the processes of egalitarianism, effective communication, and clarity over decision making are tightly connected to consensus-building. More specifically, when Jack introduced the idea of changing the introductory physics courses for life science majors to his department, he found that many faculty expressed resistance. In response, he developed a plan to begin the changes gradually, starting with tasks where he expected the least resistance: first aiming to change the textbook, then the labs, and finally the pedagogy. Multiple team members emphasized Jack's key role in bringing everyone together, resolving any issues that arose, contributing to the development of effective communication and establishing clear collaboration norms.

Following Jack's plan, the team spent about 3 months looking for a physics textbook for life science majors that they could all agree was suitable for students in their context. Eventually, the team discovered such a book. He described how the team moved forward from that point:
[...] we actually had a book that we could all agree on and teach from, and nobody had to decide arbitrarily what to drop and what to keep. So, I got a consensus. So now that I had consensus on the physics we teach, it started to become easier to say 'Well let's go a little bit further. Let's try and change our laboratories that go to support this.'

Here, we see evidence of how Jack identified that a problem existed-faculty were initially resistant to changeand came up with a plan to overcome this resistance. Throughout his interview, Jack emphasized the importance of consensus-building as a leadership approach. Other team members corroborated Jack's account that this approach was present and effective. For example, Nick described how he values Jack's emphasis on consensusbuilding and the actions Jack took to ensure that team decision-making would, for the most part, revolve around consensus-building:

I think a characteristic of him (Jack) in particular that was particularly useful was that as a consensus builder, he didn't express preconceptions or prejudice about any particular viewpoint and was very careful, in my mind at least, to validate all or most concerns, really all concerns, so that in the end when consensus was built [...] it didn't feel unfair.

Building on this story, Nick later stated that it felt that consensus-building always organically emerged, but without Jack guiding the conversation it may have been more chaotic and difficult to reach consensus. Thus, we see Jack having a key role by enacting strategic leadership on the Physics team. Moreover, we see that Jack's strategic leadership directly contributes to other team processes in our model - egalitarian power dynamics, effective communication, and clear decision-making processes - that all seem to help the Physics team.

In the Biology team, the role of the team leader (Vicky) was influential to its collaboration, in more than one way. Vicky engaged in problem-solving by identifying that initially people had different views of the team's goals. Vicky, having a background in education, introduced the team members to the literature in biology education. Vicky's actions helped to clearly communicate the literature on evidence-based education practices to the team members, helping them see value in those goals. Later on, we see that the exposure to the literature on education helped the team members understand and value the effects of practice-based learning and student-centered approach to instruction. This is captured in the following quote by Drek:

I mean, Vicky, she provided kind of a brief training (on education research) [...]. Some faculty members [...] 
they've never heard of those ideas, and they're now teaching microbiology. [...] Right now I think everyone is on the same page. But, in the beginning, [...], we didn't really have the same opinions.

Drek made the connection between having divergent ideas on the team and finally, converging them through training on the literature on education research. Vicky's contribution was crucial since she was the team leader with power over the team who organized and led these training sessions to help bring everyone on the same page. He also emphasized Vicky's efforts in reinforcing team member engagement and participation in the team's meetings:

\section{Yeah, it's all about our leader. I would say Vicky did a very good job of organizing and putting the team together, and forcing everyone to come to the meetings and contribute to the discussion. She's very good at it. [...] I think good leadership is very critical in this process. [...] I always say Vicky is the major driving force to make these things happen over here. [...] that's why a strong leader is very, very critical.}

Team member commitment was evident in the Biology team. However, according to the team leader, Vicky, there was a point in time where certain team members' actions reflected a lack of team member commitment. This was eventually resolved by the actions of the team leader, Vicky, who described this incident, below:

[...] there were a couple of members who just sorta came when they felt like it. And so I was kind of like, well do you guys value this or not? [..] I actually went and talked to the one who was just casually showing up. And I went and talked to him and I said, [...] 'how can we get you to come', basically is what I was doing. So we had a good chat and he ended up coming much more regularly after that.

In this team, Vicky's plans and actions initiated processes of team member commitment and effective communication on the team's goals.

\section{Discussion}

Our purpose is to identify team processes and emergent states of successful teams in the context of higher education. This study found three emergent states and five team process subcategories and developed definitions for each. As stated by Mathieu et al. (2008), "the distinction between process and emergent states appears to be gaining acceptance in the literature and helping to sort out the mediator portion of many team effectiveness models." (p. 432) They also point out that measures of processes and states are highly correlated. Our findings agree with this statement, as we saw numerous links between the team processes and the emergent states. However, in this paper, we present and discuss the connections between the constructs that were evident in more than two teams. Below, we elaborate on the findings of the present study by discussing the role and origins of each of the three identified emergent states and how the team processes contribute to these states. We also discuss the outstanding role of the strategic leadership process in influencing the other four team processes. Finally, we weave together our results with results from the literature in a variety of contexts.

\section{Role and origins of shared vision}

In our analysis, we find evidence that a shared vision is important for instructional change teams' effectiveness. We find that teams that had developed a shared vision also reached their goals, sustained their collaboration and the instructional changes, and improved their abilitcollaborationteam. Research from business management corroborates this emerging idea that shared vision is critical for teams (Katzenbach and Smith 1993; Kozlowski and Ilgen 2006). When discussing what differentiates a team from a group, Katzenbach \& Smith (1993) emphasize that the essence of a team is having a common purpose that team members can believe in. In a later review of the literature on teams, Kozlowski \& Ilgen (2006) use the term collective climate to refer to a shared understanding among team members about the core mission and objectives of their team, which strongly overlaps with our definition of "shared vision." The authors conclude that a collective climate is a key emergent cognitive structure that shapes processes relevant to team goals and accomplishments. In a more focused study, Pearce \& Ensley (2004) assessed the effect of team members' perceptions of team innovation effectiveness on a shared vision and the reciprocal process in a longitudinal quantitative study on teams. They found that shared vision and innovation effectiveness positively and cyclically influence each other. The importance of a shared vision is also evident in higher education literature (e.g., Quan et al. (2019)). Quan et al. developed a model of six principles that enact sustainable departmental change. The authors identified shared vision as one of these principles claiming that its development supports and guides the team in achieving the outcome.

We also see evidence that effective communication and clear decision-making processes influence the development of shared vision in instructional change teams. This influence was evident in all four teams. The Material Science and Physics teams openly discuss, work through conflicts, and establish clarity over the decision-making process. They also developed a shared vision over the team's goals and the ways to work together. On the other hand, we see the influence of effective communication on a shared vision by the lack of effective communication. 
The Biology team struggled to adopt a clear communication style, and we also find that the team members hold mixed views on how the team's outcomes should be implemented. Moreover, the Engineering team did not openly talk about expectations and responsibilities, which led to team members' confusion about the new goals that the team is working on. The connection between the development of a shared vision and effective communication is not new. Senge (1990) says "visions that are genuinely shared require ongoing conversation where individuals not only feel free to express their dreams but learn how to listen to each others' dreams" (p. 203). We also see some evidence of this dynamic in higher education literature on science teams. For example, in a recent study of medical researchers, interviewees expressed that articulating some concrete shared goals early on and engaging in frequent communication (formally and informally) helped them to develop a shared understanding (Vogel et al. 2014). Zaccaro et al. (2001) argue that team members reduce the amount of processing and communication when having a shared vision on a team since they can better understand each other's actions. These findings corroborate the idea that there is a relationship between these two constructs in our model.

\section{Role and origins of psychological safety}

These findings support the importance of psychological safety in the success of instructional change teams. Specifically, when team members perceive a low risk of negative emotional or career-related consequences, they improve their ability to collaborate as a team, shifting towards a positive and team-oriented direction, and sustain their collaboration and/or the instructional changes. Researchers in business management and in healthcare who study teams have extensively examined the construct of psychological safety on team performance (Bradley et al. 2012; Edmondson 1999; Sanner and Bunderson 2015). In particular, psychological safety has a strong, positive effect on team performance for complex and knowledge-demanding tasks, but this effect decreases significantly as tasks become simpler and less knowledgeintense. We consider this finding consistent with our claim that psychological safety is important for instructional change teams (Sanner and Bunderson 2015). In the present study, team members undertake a demanding task (redesigning instruction) that can be difficult even for those trained in education. In that sense, we see that the nature of these teams' task is complex and knowledgeintense. Another study on instructional change teams directly supports the effect of psychological safety on team outcomes in our same context. A study administered a survey to 21 multidisciplinary teams from two medical schools in Europe that were reforming their curricula (Stalmeijer et al. 2007). The researchers aimed to determine the relationship between team factors and educational outcomes of the reformed courses. The study revealed that when team members feel psychologically safe, they achieve better results in terms of the quality of assessment and a course's educational effectiveness. This provides further evidence of the importance of psychological safety on team performance.

We also find evidence that egalitarian power dynamics contribute to the development of psychological safety in instructional change teams. All the teams in our study cultivated a climate of open and non-judgmental communication that allowed low-ranked team members to feel safe sharing their opinions and concerns. The influence of egalitarian power dynamics on psychological safety is evident by several team members' stories. In particular, we find examples where team members with lower institutional rank describe how their feelings towards working with senior faculty have shifted since they started working on the team. They describe how comfortable they feel in expressing their ideas on the team, mainly due to the egalitarian nature of the interaction between team members. Edmonson (2004) proposes that psychological safety may enable specific team behaviors, such as help-seeking and ask for feedback. However, egalitarianism processes in team members' interactions can help create a sense of psychological safety, which also informs team behavior such as help-seeking. In the Material Science team, a team member who is a junior faculty in the department mentioned that initially, she felt intimidated by the senior faculty and was afraid to ask questions. This example suggests that team members' power dynamics affect team members' behavior, a finding that is in agreement with Lee (1997). In that study, survey results revealed that in a hospital that has recently introduced a new computer technology for processing medication orders, participants (93 nurses and 103 physicians) were more likely to seek help from equal-status rather than unequal-status (higher or lower) individuals. In the example of the Material Science team and the other teams in our dataset, we see that when power dynamics were reduced, teams develop psychological safety, and the relationships between individuals become more collaborative.

\section{Role and origins of team cohesion}

Our findings indicate that the emergent state of team cohesion plays a role in instructional change teams' effectiveness. Specifically, our analysis suggests that highly cohesive instructional change teams may improve their ability to collaborate and be more eager to continue working together. For example, the Material Science team, which had pre-existing friendly relationships between a subset of team members when forming the team, expanded its spirit of positive social relationships to everyone else that eventually joined the team. The 
team members reported being eager to continue working together and are meeting weekly, even without any financial support. This indicates the relationship between strong team cohesion and the sustainability of the team's outcomes. Team cohesion is the most studied emergent state in the teams' literature (Mathieu et al. 2008; Kozlowski and Ilgen 2006). In the organizational literature, cohesion has been extensively studied as one of the team characteristics influencing team outcomes (Beal et al. 2003; Kozlowski and Ilgen 2006). Beal et al's (2003) meta-analysis of group cohesion and performance found that cohesion is significantly related to both the team behavior (what members do) and team outcomes. Similarly, a review study by Kozlowski and Ilgen (2006) concludes that teams with greater collective tasks and interpersonal commitment are more likely to be effective. Zaccaro et al. (2001) claim that teams with a strong cohesion around their task will persist at the task, even when facing possible failure. Our records regarding one of our teams align with this statement. In particular, the Biology team had a strong cohesion around the task. For the Biology team, the students' negative reactions to the first implementation of the instructional changes were not perceived as a failure but as feedback on whether or how the instructional outcomes should be improved.

Looking more closely at the teams that had strong team cohesion, we see that the process of team member commitment influences this emergent state. Team member commitment was evident in the Material Science team in particular. We noticed that team members demonstrate high levels of engagement and interest in the team's task. This was evident because these team members contribute their ideas to the team and regularly attend team meetings even when they do not teach the course(s) under revision. We also see that this frequent interaction and active engagement on the team's task helped maintain team cohesion in strong interpersonal relations. Team members described how new members joined later the team and "blended in the spirit of the team." In the Engineering team, we see a lack of team member commitment and a lack of team cohesion between senior and junior team members. The lack of team cohesion negatively influenced the team's ability to collaborate by causing frustration for certain members about the reported imbalance in team members' efforts. Overall, the team was not very cohesive, but highly committed individuals (senior team members) did have strong team cohesion who persisted on the team's task. This phenomenon has been explained in psychology with the term of social compensation, where highly contributing individuals will increase their efforts when working collectively to compensate for their co-workers' insufficient performance. As Williams \& Karau (1991) discuss, one of the reasons that could lead to the phenomenon of social compensation on a team is when an individual views the success of the team's task as important or meaningful.

\section{Role and effects of strategic leadership}

As discussed above, all five team processes were important for creating productive emergent states. However, strategic leadership is pulled out in the model as the process that influences the other four processes. In most of the teams we studied, leadership actions were mainly initiated by a single individual who was the formal team leader. On the Material Science team, leadership actions were shared by the team members. The role of leadership processes on team effectiveness has been extensively examined in the organizational literature (e.g., Zaccaro et al. (2001); Kozlowski and Ilgen (2006)). Zaccaro et al. (2001) argue that effective leadership is the most salient element in organizational teams' success. Our results generally align with this idea. In particular, we define the process of strategic leadership as inherent in developing and maintaining those team processes that seem influential for instructional change team effectiveness. Our definition states that the critical aspects for facilitating strategic leadership involve establishing processes that facilitate consensus-building, acting proactively to avoid anticipated threats, and/or overcoming existing barriers towards team success. This aligns with functional leadership theory, which states that team leadership is the process of identifying and satisfying the critical team needs for team success (McGrath 1962).

The overall relationship between strategic leadership and shared vision is supported in the literature on organizational teams (Kozlowski et al. 1996; Zaccaro et al. 2001; Kozlowski and Ilgen 2006). For example, Kozlowski \& Ilgen (2006) argue that leadership is a factor that acts as a leverage point for shaping a collective climate (shared understanding among team members about the core mission and objectives of their team) to influence team effectiveness. However, there is limited empirical evidence on the ways that leadership influences the development of a shared vision (van Ginkel and van Knippenberg 2012). In our data, we see evidence of a relationship between strategic leadership and the process of effective communication, which in turn contributes to the development of a shared vision. As we discussed above, teams that developed a shared vision over the team's goals and the action steps to reach those goals had also developed effective communication in their interactions. In particular, we see that effective communication is enacted through the actions of strategic leadership. Under the team leader's guidance, the Physics team was effectively communicating when establishing the concrete team goals collectively, coordinating team actions towards goal attainment, and clearly stating and agreeing on how decisions will be made. Morgeson, DeRue, \& Karam (2010) identify it as 
the leader's responsibility to articulate the team's goals and ensure that the team has an aligned understanding of the mission. Research in organizational change suggests that a leader's communication is important for enacting change. For example, in a survey study on organizational change, Gilley, Gilley, \& McMillan (2009) found that a leader's effective communication about change predicted a leader's effectiveness with organizational change. The link between strategic leadership and effective communication is also evident in the healthcare literature. de Casterle et al. (2008) conducted a case-study to investigate the impact of the Clinical Leadership development Project on the clinical leader, the nursing team, and the caregiving process. They found that the team leader promoted effective communication in openly expressing expectations, establishing agreements, and using a straightforward communication method.

In our data, we see evidence of a relationship between strategic leadership and egalitarian power dynamics, which contributes to the development of psychological safety. The overall relationship between strategic leadership and psychological safety aligns with Carmeli, ReiterPalmon, \& Ziv (2010), who conducted a longitudinal quantitative study to examine how the behavior of a leader is open, available, and accessible impacts psychological safety and employee creativity. They found that this type of leader behavior is positively related to psychological safety in the workplace. We find that teams that developed psychological safety had also developed egalitarian power dynamics processes and that strategic leadership processes can play a key role in generating these egalitarian power dynamics. Team leaders' actions in enacting processes of egalitarian power dynamics are consistent with the findings of Nembhard \& Edmondson (2006), who introduced the construct of leader inclusiveness that refers to words and deeds by leaders that invite others' contributions.

We find that the process of team member commitment, which is linked to the development of team cohesion, can be enacted by the actions of strategic leadership in several ways. First, the team leader carefully selects to include those individuals on the team interested in the broad idea of the team's task (e.g., Material Science team). DeHart (2017) encourages team members to get to know potential teammates before committing to collaborate. The team leader also identifies individual team members' interests and concerns to assign them sub-tasks that align with their interests (e.g., Physics team). Finally, the team leader discusses with team members who demonstrate low levels of engagement by emphasizing the importance of those members' contributions to the team and developing a better sense of ownership for the team's task (e.g., Biology team). We encountered strategic leadership actions that enacted and/or reinforced the processes of team member commitment. Although limited, we found evidence in the literature that suggests a relationship between leadership and team member commitment. In particular, Arnold, Barling, \& Kelloway (2001) found that leadership that encourages, inspires, and motivates employees predicts the development of team commitment.

\section{Limitations}

We identify several limitations that might have influenced the results. The first is a selection bias towards well-functioning teams, since all the teams we studied achieved (or are making good progress towards achieving) to some degree most of the intended outcomes. Project leaders whose teams were experiencing severe challenges might have been less willing to participate in our study and/or connect us to those team members. Including data from only successful teams limits our understanding of the scope of challenges that instructional change teams could face. Another limitation is the incomplete sampling of all the team members in each team. When we could not capture the perspectives of all team members, it may have limited our understanding of the team dynamics. Third, response bias may have been present in our interviews. We interviewed team members with various institutional roles (including graduate students, staff, and faculty members). In addition to not wanting to provide socially unfavorable responses, team members may have feared that negative feedback would ultimately be seen and identified by other team members, which could be particularly prevalent for team members of lower institutional rank. Although we cannot tell who spoke freely and who did not, we must consider the potential for response bias. Finally, our data represent a snapshot of the history of these teams. While some team members described their team's collaboration in past years, their accounts may not fully represent their feelings and perspectives about their collaborations at earlier times due to possible memory bias.

\section{Conclusions}

Team-based initiatives have great potential to contribute to widespread and lasting change in undergraduate STEM education. Team-based initiatives can also lead to negative outcomes, such as increased interpersonal tension between colleagues and resentment or frustration. While much research has been conducted on teams in other contexts, little research has been conducted to pull relevant pieces of this literature together and illustrate what successful collaboration can look like in the context of higher education instructional change.

In this study, we elicited team members' perspectives on their collaboration to identify key aspects of how instructional change teams work together, expanding on our initial model (Olmstead et al. 2019). We identified three 
emergent states that seem to contribute to favorable team outcomes: shared vision, psychological safety, and team cohesion. We also identified five processes that seem to support these emergent states: egalitarian power dynamics, team member commitment, effective communication, clear decision-making processes, and strategic leadership. We find that the first four-team processes can improve team outcomes by generating favorable emergent states, while strategic leadership indirectly influences the emergent states by shaping the other processes. While these processes may be important for team success, strategic leadership may have an outsized effect on instructional change team outcomes.

These results provide new guidance to change leaders who are currently involved in team-based instructional change work. Although many of the aspects we identified as important to instructional change teams are present in the broader literature on organizational change (egalitarianism, shared vision, psychological safety, etc.), our work brings these ideas together in a cohesive way. More importantly, the examples provided in this paper demonstrate the relevance of these constructs for instructional change teams and illustrate what they can look like when present (or not present) in higher education contexts. Change leaders can thus use the emergent states and team processes we identified to help diagnose the health of their collaborations and consider what an improved mode of operation might be. Importantly, we do not advocate that there is one best way for instructional change teams to operate. The variety and complexity in the four cases presented here already start to counteract this possibility. Instead, we imagine that considering the constructs in our model could help change leaders gain situation-specific insights about their teams' strengths and weaknesses that might otherwise go unnoticed.

Our results also present a starting point for future research that can further enrich our understanding of the complex nature of teamwork in this context. Our analysis revealed a vast number of connections between the team processes and emergent states. For example, we saw that egalitarian power dynamics can contribute to psychological safety, team member commitment can contribute to team cohesion, and a combination of effective communication and clear decision-making processes can contribute to a shared vision. However, this study alone could not capture the relative importance of these contributions on a typical team. A future, large-scale study that examines similar data from many teams could uncover trends in the interrelationships between these team processes and emergent states and the influence of the emergent states on specific team outcomes. Moreover, we saw hints of connections between the team inputs and the team processes as we built up this model. For example, we found evidence that who participates on the team can influence team member commitment. For example, team members who were compelled to participate because of their teaching courses rather than their intrinsic interest were less committed to their team's task. Future studies that explicitly set out to explore this aspect of our model could reveal more about these connections. More broadly, future research could reveal missing pieces from our current model that are also important for instructional change team success.

This study identified aspects of team-based collaboration and provided context on how these aspects play out in STEM undergraduate instructional change. However, teamwork is needed and pursued in many aspects of academia and higher education to tackle a range of systemic inequities. Our model could be used as a starting point for understanding how such teams can work together effectively. There is much left to be explored, and we encourage other researchers to take up and test our model in ways that will bolster critical efforts to generate systemic change in higher education.

\section{Supplementary Information}

The online version contains supplementary material available at https://doi.org/10.1186/s40594-021-00273-4

Additional file 1: Interview protocol questions with team members. Additional file 2: Team inputs.

\section{Abbreviations}

STEM: Science, technology, engineering, and mathematics; US: United States

\section{Acknowledgements}

We thank the undergraduate student Audiel Maldonado whose contribution helped validate the results of this study. We are also grateful to the participants who agreed to be interviewed for this study and to everyone who gave us feedback as we developed this model. We are thankful to the team members who agreed to be interviewed for this study and to everyone who gave us feedback as we developed this model.

\section{Authors' contributions}

The authors collaboratively developed and refined the model of instructional change teams, as well as the overall study design. DS took primary responsibility for the data collection, data analysis, and writing. AO provided feedback throughout and assisted with the data analysis. All authors read, edited, and approved this manuscript. All authors agree to be accountable for all aspects of the work in ensuring that questions related to the accuracy or integrity of any part of it are appropriately investigated and resolved.

\section{Funding}

This work was supported by the National Science Foundation, Division of Undergraduate Education under the grant award 1525393. Any opinions, findings, conclusions, or recommendations expressed in this material are those of the authors and do not necessarily reflect the views of the National Science Foundation.

\section{Availability of data and materials}

The data that support the findings of this study are available on request from the corresponding author. The data are not publicly available due to them containing information that could compromise research participant and/or team member privacy.

\section{Competing interests}

The authors declare that they have no competing interests. 


\section{Author details}

${ }^{1}$ Center for Research on Instructional Change in Postsecondary Education, Western Michigan University, 1903 W. Michigan Ave., 49008 Kalamazoo, USA. ${ }^{2}$ Mallinson Institute for Science Education, Western Michigan University, 1903 W. Michigan Ave., 49008 Kalamazoo, USA. ${ }^{3}$ Department of Physics, Texas State University, 601 University Drive, 78666 San Marcos, USA. ${ }^{4}$ Department of Physics, Western Michigan University, 1903 W. Michigan Ave., 49008 Kalamazoo, USA. ${ }^{5}$ Department of Educational Leadership, Research and Technology, Western Michigan University, 1903 W. Michigan Ave., 49008 Kalamazoo, USA

Received: 25 June 2020 Accepted: 18 January 2021

Published online: 02 April 2021

\section{References}

Addis, E.A., Quardokus, K.M., Bassham, D.C., Becraft, P.W., Boury, N., Coffman, C.R., Colbert, J.T., Powell-Coffman, J.A. (2013). Implementing pedagogical change in introductory biology courses through the use of faculty learning communities. Journal of College Science Teaching, 43, 22-29.

Andrews, T.C., Conaway, E.P., Zhao, J., Dolan, E.L. (2016). Colleagues as change agents: How department networks and opinion leaders influence teaching at a single research university. CBE-Life Sciences Education, 15(2), 15.

Arnold, K.A., Barling, J., Kelloway, E.K. (2001). Transformational leadership or the iron cage: Which predicts trust, commitment and team efficacy? Leadership and Organization Development Journal, 22(7), 315-320.

Beal, D.J., Cohen, R.R., Burke, M.J., McLendon, C.L. (2003). Cohesion and performance in groups: a meta-analytic clarification of construct relations. Journal of Applied Psychology, 6, 989-1004.

Becker, P.H. (1993). Common pitfalls in published grounded theory research. Qualitative Health Research, 3(2), 254-260.

Bradley, B.H., Postlethwaite, B.E., Klotz, A.C., Hamdani, M.R., Brown, K.G. (2012). Reaping the benefits of task conflict in teams: The critical role of team psychological safety climate. Journal of Applied Psychology, 97(1), 151-158.

Carmeli, A., Reiter-Palmon, R., Ziv, E. (2010). Inclusive leadership and employee involvement in creative tasks in the workplace: The mediating role of psychological safety. Creativity Research Journal, 22(3), 250-260.

Chasteen, S.V., Perkins, K.K., Beale, P.D., Pollock, S.J., Wieman, C.E. (2011). A thoughtful approach to instruction: course transformation for the rest of us. Journal of College Science Teaching, 40, 70-76.

Chasteen, S.V., Wilcox, B., Caballero, M.D., Perkins, K.K., Pollock, S.J., Wieman, C.E. (2015). Educational transformation in upper-division physics: The Science Education Initiative model, outcomes, and lessons learned. Physical Review Special Topics - Physics Education Research, 11(2), 201-210

Corbo, J.C., Reinholz, D.L., Dancy, M.H., Deetz, S., Finkelstein, N. (2016). A framework for transforming departmental culture to support educational innovation. Physical Review - Physics Education Research, 12, 010113.

Cox, M.D. (2001). Faculty learning communities: Change agents for transforming institutions into learning organizations. To Improve the Academy, 19, 69-93.

Cox, M.D. (2004). Introduction to faculty learning communities. New Directions for Teaching and Learning, 97, 5-23.

de Casterle, B.D., Willemse, A., Verschueren, M., Milisen, K. (2008). Impact of clinical leadership development on the clinical leader, nursing team and care-giving process: A case study. Journal of Nursing Management, 16, 753-763.

DeHart, D. (2017). Team science: A qualitative study of benefits, challenges, and lessons learned. Social Science Journal, 54, 458-467.

Edmondson, A. (1999). Psychological safety and learning behavior in work teams. Administrative Science Quarterly, 44, 350-383.

Edmonson, A.C. (2004). Psychological safety, trust and learning in organizations: A group-level lens. In R.M. Kramer \& K.S. Cook (Eds.), Trust and distrust across organizational contexts: Dilemmas and approaches (pp. 239-273). New York: Russell Sage.

Fiore, S. (2007). Interdisciplinarity as teamwork: How the science teams can inform team science. Small Group Research, 39, 251-277.

Gast, I., Schildkamp, K., van der Veen, J.T. (2017). Team-based professional development interventions in higher education: A systematic review. Review of Educational Research, 87(4), 736-767.

Gibson, B., \& Hartman, J. (2013). Rediscovering grounded theory. Thousand Oaks, CA: Sage.
Gilley, A., Gilley, J., McMillan, H. (2009). Organizational change: Motivation, communication, and leadership effectiveness. Performance Improvement Quarterly, 21(4), 75-94.

Gilley, A., \& Kerno, S.J. (2010). Groups, teams, and communities of practice: A comparison. Advances in Developing Human Resources, 12(1), 46-60.

Glazer, B. (1978). Theoretical sensitivity: Advances in the methodology of grounded theory. Mill Valley: Sociology Press.

Guzzo, R.A., \& Dickson, M.W. (1996). Teams in organizations: Recent research on performance and effectiveness. Annual Review of Psychology, 47, 307-338.

Henderson, C., Beach, A., Finkelstein, N. (2011). Facilitating change in undergraduate STEM instructional practices: An analytic review of the literature. Journal of Research in Science Teaching, 48, 952-984.

Ilgen, D.R., Hollenbeck, J.R., Johnson, M., Jundt, D. (2005). Teams in organizations: From input-process-output models to IMOI models. Annual Review of Psychology, 56, 517-543.

Jehn, K.A., Northcraft, G.B., Neale, M.A. (1999). Why differences make a difference: A field study of diversity, conflict, and performance in workgroups. Administrative Science Quarterly, 44(4), 741-763.

Karlgaard, R., \& Malone, M.S. (2015). Team genius: The new science of high-performing teams. New York: HarperCollins.

Katzenbach, J.R., \& Smith, D.K. (1993). The discipline of teams. Harvard Business Review, 71, 111-120.

Kezar, A. (2001). Understanding and facilitating organizational change in the 21st century. San Francisco, CA: Jossey-Bass.

Kezar, A. \& Gehrke, S. (2015). Communities of transformation and their work scaling STEM reform. Los Angeles, CA: Pullias Center for Higher Education.

Kozlowski, S.W.J., Gully, S.M., Salas, E., Cannon-Bowers, J.A. (1996). Team leadership and development: Theory, principles, and guidelines for training leaders and teams. Greenwich, CT: JAl: Doubleday.

Kozlowski, S.W.J., \& Ilgen, D.R. (2006). Enhancing the effectiveness of work groups and teams. Psychological Science in the Public Interest, 7, 77-124.

Lau, D.C., \& Murnighan, J.K. (1998). Demographic diversity and faultlines: The compositional dynamics of organizational groups. Academy of Management Review, 23, 325-340.

Lee, F. (1997). When the going gets tough, do the tough ask for help? Help seeking and power motivation in organizations. Organizational Behavior and Human Decision Processes, 72(3), 336-363.

Leggat, S.G. (2007). Effective healthcare teams require effective team members: Defining teamwork competencies. BMC Health Services Research, 17(7), 1-10.

Mannix, E., \& Neale, M.A. (2005). What differences make a difference? Psychological Science in Public Interest, 6, 31-55.

Marks, M.A., Mathieu, J.E., Zaccaro, S. (2001). A temporally based framework and taxonomy of team processes. Academy of Management Review, 26, 356-376.

Mathieu, J.E., Maynard, M.T., Rapp, T.L., Gilson, L. (2008). Team effectiveness 1997-2007: A review of recent advancements and a glimpse into the future. Journal of Management, 34(3), 410-476.

McGrath, J.E. (1962). Leadership behavior: Some requirements for leadership training. Washington, DC: U.S. Civil Service Commission, Office of Career Development.

Morgeson, F.P., DeRue, D.S., Karam, E.P. (2010). Leadership in teams: A functional approach to understanding leadership structures and processes. Journal of Management, 36, 5-39.

Nembhard, I.M., \& Edmondson, A.C. (2006). Making it safe: The effects of leader inclusiveness and professional status on psychological safety and improvement efforts in health care teams. Journal of Organizational Behavior, 27(7), 941-966.

Olmstead, A., Beach, A., Henderson, C. (2019). Supporting improvements to undergraduate STEM instruction: An emerging model for understanding instructional change teams. International Journal of STEM Education, 6, 20.

Pearce, C.L., \& Ensley, M.D. (2004). A reciprocal and longitudinal investigation of the innovation process: The central role of shared vision in product and process innovation teams (PPITs). Journal of Organizational Behavior, 25, 259-278

President's Council of Advisors on Science and Technology (US) (2010). Prepare and Inspire: $K-12$ education in science, technology, engineering, and math (STEM) for America's Future. Washington, DC. Executive Office of the President, President's Council of Advisors on Science and Technology.

Quan, G.M., Corbo, J.C., Finkelstein, N.D., Pawlak, A., Falkenberg, K., Geanious, C., Ngai, C., Smith, C., Wise, S., Pilgrim, M.E., Reinholz, D.L. (2019). Designing for institutional transformation: Six principles for department-level interventions. Physical Review Physics Education Research, 15(1), 010141. 
Quinn, B.A. (1995). Understanding the differences between committees and teams. Library Administration \& Management, 9, 111-116.

Reinholz, D.L., \& Apkarian, N. (2018). Four frames for systemic change in STEM departments. International Journal of STEM Education, 5(3), 1-10.

Richlin, L., \& Cox, M.D. (2004). Developing scholarly teaching and the scholarship of teaching and learning through faculty learning communities. New Directions for Teaching and Learning, 2004, 127-135.

Sanner, B., \& Bunderson, J.S. (2015). When feeling safe isn't enough: Contextualizing models of safety and learning in teams. Organizational Psychology Review, 5, 224-243.

Senge, P.M. (1990). The fifth discipline: The art and practice of the learning organization. Broadway, New York, New York 10036: Doubleday.

Stalmeijer, R.E., Gijselaers, W.H., Wolfhagen, I., Harendza, S., Scherpbier, A. (2007). How interdisciplinary teams can create multi-disciplinary education: The interplay between team processes and educational quality Medical Education, 4, 1059-1066.

Stasser, G., Vaughan, S.I., Stewart, D.D. (2000). Pooling unshared information: The benefits of knowing how access to information is distributed among group members. Organizational Behavior and Human Decision Processes, 82 102-116.

van Ginkel, W.P., \& van Knippenberg, D. (2012). Group leadership and shared task representations in decision making groups. Leadership Quarterly, 23, 94-106.

Vogel, A.L., Stipelman, B.A., Hall, K.L., Nebeling, L., Stokols, D., Spruijt-Metz, D. (2014). Pioneering the transdisciplinary team science approach: Lessons learned from National Cancer Institute grantees. Journal of Translational Medicine Epidemiology, 2(2), 1027.

Ward, H.C., \& Selvester, P.M. (2012). Faculty learning communities: Improving teaching in higher education. Educational Studies, 38(1), 111-121.

Weaver, G.C., Burgess, W.D., Childress, A.L., Slakey, L. (2016). Transforming institutions: Undergraduate STEM education for the 21st century. West Lafayette, Indiana: Purdue University Press.

Williams, K.D., \& Karau, S.J. (1991). Social loafing and social compensation: The effects of expectations of co-worker performance. Journal of Personality and Social Psychology, 61, 570-581.

Woolley, A.W., Chabris, C.F., Pentland, A., Hashmi, N., Malone, T. (2010). Evidence for a collective intelligence factor in the performance of human groups. Science, 330, 686-689.

Wuchty, S., Jones, B.F., Uzzi, B. (2007). The increasing dominance of teams in production of knowledge. Science, 316, 1036-1039.

Zaccaro, S.J., Rittman, A.L., Marks, M.A. (2001). Team leadership. Leadership Quarterly, 12, 415-483.

\section{Publisher's Note}

Springer Nature remains neutral with regard to jurisdictional claims in published maps and institutional affiliations.

\section{Submit your manuscript to a SpringerOpen ${ }^{\circ}$ journal and benefit from:}

- Convenient online submission

- Rigorous peer review

- Open access: articles freely available online

- High visibility within the field

- Retaining the copyright to your article

Submit your next manuscript at $\gg$ springeropen.com 